\section{CANGER}

\section{Low carb, low tumour growth}

A low-carbohydrate, highprotein diet slowed tumour growth in mice compared with a typical high-carbohydrate Western-style diet.

Gerald Krystal at the BC Cancer Research Centre in Vancouver, Canada, and his colleagues compared the growth of both human and mouse tumours in mice fed diets comprising $8 \%, 10 \%$, $15 \%$ or $55 \%$ carbohydrate. All four diets had the same calorie content. At the $10 \%$ and $15 \%$ levels, mice showed slower tumour growth than animals eating the high-carbohydrate diet, and did not lose weight.

In mice engineered to develop breast cancer, almost half of the animals on the Western diet developed tumours by one year of age, whereas none on the $15 \%$-carb diet did. The authors suggest that for cancers associated with particularly high bloodglucose levels, limiting dietary carbohydrates could aid in treatment.

Cancer Res. 71, 4484-4493 (2011)

\section{ASTRONOMY}

\section{Nuclear network detects fireball}

An international network of sensors designed to detect illicit nuclear blasts has been used to study the fiery break-up of a large meteoroid over Indonesia in October 2009.

Every decade or so, a meteoroid a few metres in diameter explodes in Earth's atmosphere with a force equivalent to that of a mid-sized nuclear weapon. Elizabeth Silber at the University of Western Ontario in London, Canada, and her group analysed low-frequency sound-wave data from 17 sensors maintained by the Comprehensive Nuclear-TestBan Treaty Organization. The team found that the explosion was probably equivalent to between 8 and 67 kilotonnes of the explosive chemical TNT.

They conclude that the network could be used to study future meteoroid strikes, improving our understanding of near-Earth objects.

Geophys. Res. Lett. doi:10.1029/2011GL047633 (2011)

\section{CLIMATE CHANGE}

\section{Extra warming near Greenland}

Rising ocean temperatures are already accelerating the melting of Greenland's coastal glaciers. Projections from 19 climate models now suggest that, with growing greenhousegas emissions, the maximum warming of subsurface waters around the island will be almost double the global average increase during the twenty-first century.

Jianjun Yin at the University of Arizona in Tucson and his co-workers modelled the impact of a modest rise in greenhouse-gas emissions on ocean temperatures around Greenland and Antarctica. They predict that waters 200-500 metres below the surface around Greenland will warm by $1.7-2.0^{\circ} \mathrm{C}$ by the end of this century. Meanwhile, Antarctic Ocean temperatures will increase by roughly $0.5^{\circ} \mathrm{C}$.

The authors say that differences in ocean circulation patterns are a key factor in these responses.

Nature Geosci. doi:10.1038/ ngeo1189 (2011)

\section{MICROBIOLOGY}

\section{A key for bacterial entry}

A protein that allows some bacteria to cling to and invade host cells could be a target for combating infection.

Kim Orth and her colleagues at the University of Texas Southwestern Medical Center in Dallas searched for such proteins in the bacterium Vibrio parahaemolyticus, which can cause food poisoning. They found MAM7, a protein that is expressed in the bacterial

COMMUNITY CHOICE

The most viewed papers in science

\title{
Barnacles help battle biofilms
}

\section{HIGHLY READ \\ on pubs.acs.org in May}

By exploiting barnacles' remarkable clinging ability, researchers have anchored antibacterial 'polymer brushes' to the surface of steel. This could prevent the formation of dangerous bacterial biofilms on the surfaces of medical devices.

En-Tang Kang at the National University of Singapore and his colleagues coated stainless steel with a thin layer of cement harvested from Amphibalanus amphitrite barnacles. They then used this cement to initiate the growth of polymer chains of 2-hydroxyethyl methacrylate, which was coupled with chitosan, an antibacterial molecule. The treated steel lowered the adhesion of the bacterium Escherichia coli and cut survival to less than $20 \%$. Normal steel did not affect bacterial viability. Langmuir 27, 7065-7076 (2011)

outer membrane. Deleting the $M A M 7$ gene decreased the bacterium's ability to bind to and kill human and mouse cells. Nematode worms fed the pathogenic bacterium died (pictured bottom) faster than did those exposed to harmless Escherichia coli (top).

Exposure of human cells to benign $E$. coli engineered to express MAM7 rendered the cells more resistant to infection by $V$. parahaemolyticus and other pathogenic bacteria. This suggests that the E. coli's MAM7 blocked key binding sites needed by the bacterial invaders, providing a new way to fight infection.

Proc. Natl Acad. Sci. USA doi:10.1073/pnas.1102360108 (2011)
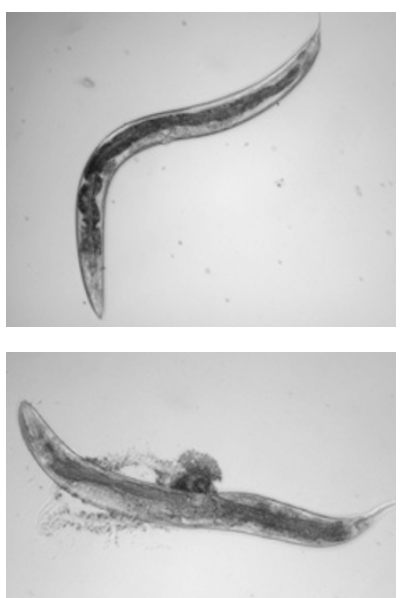

\section{NEUROSCIENCE \\ Protein brings death to myelin}

A protein on the surface of certain brain cells can halt production of the myelin sheaths that surround and insulate nerve fibres. The protein, DR6, could be a target of treatments for multiple sclerosis, a disease marked by myelin loss.

Sha Mi at Biogen Idec in Cambridge, Massachusetts, and her colleagues discovered that overexpression of DR6 causes the myelinproducing brain cells, called oligodendrocytes, to undergo programmed cell death. Antibodies that block DR6 boosted myelin production in cultured oligodendrocytes, and one antibody even reversed myelin damage in a rat model of multiple sclerosis. The post-mortem brains of three patients with multiple sclerosis contained more DR6expressing cells than brains of people without the condition. Nature Med. doi:10.1038/ nm.2373 (2011)

\section{ONATURE.COM}

For the latest research published by Naturevisit:

www.nature.com/latestresearch 